\title{
Prophylactic Use of Endoclips Post-polypectomy: To Bleed or Not to Bleed?
}

\author{
Hugh James Freeman
}

Published online: 23 April 2014

(C) Springer Science+Business Media New York 2014

In recent decades, colonoscopic methods have enabled complete endoscopic excision of benign and malignant colonic polyps $[1,2]$. Removal of even sessile or depressed colon neoplastic lesions by endoscopic mucosal resection (EMR) or endoscopic submucosal dissection (ESD) is now possible, as is management of complications including post-polypectomy bleeding. Specific "polyp factors" (e.g., large polyp size over $2 \mathrm{~cm}$ ) and "patient factors" (e.g., anticoagulant use) can increase bleeding risk at the time of polyp resection as well as the risk for subsequent or delayed bleeding, sometimes reported to develop days to weeks later [3, 4].

A relatively easy-to-use method to control bleeding events in the upper and lower gastrointestinal tract has entailed endoscopic application of hemoclips. In the colon, hemoclips control bleeding from a wide range of causes, including bleeding ulcers, diverticula, angiodysplasia, Dieulafoy's lesions, and the site of colonoscopically removed or biopsied polyps [5].

In recent years, some endoscopists have used hemoclips as bleeding prophylaxis, particularly in high risk settings. The procedure is relatively simple to perform, but the overall cost of prophylactic hemoclip application is likely to be significant. Feagins and colleagues from Texas describe their experience in a recent issue of Digestive Diseases and Sciences [6] in a retrospective case-control study of delayed post-polypectomy (within 30 days) bleeding in patients treated with prophylactic application of hemoclips. Controls were matched based on risk factors for post-polypectomy bleeding including polyp size,

\section{H. J. Freeman $(\square)$}

Department of Medicine (Gastroenterology), University of British Columbia, 2211 Wesbrook Mall, Vancouver, BC V6T 1W5, Canada

e-mail: hugfree@shaw.ca morphology, technique of polyp removal, number of polyps removed, and anticoagulant use. No differences in postpolypectomy bleeding were manifest between the prophylactic hemoclip group and a matched control group i.e., prophylactic hemoclips were not used. Interestingly, 3 of 184 in the prophylactic group had delayed bleeding, compared with only 1 of 184 in the control group. The authors concluded that the application of prophylactic hemoclips may be questioned with respect to effectiveness and cost.

Other relevant studies include Shioji et al. [7], who reported on their experience with delayed bleeding from post-polypectomy ulcers. Patients were assigned to a prophylactic clip group and a no clip group. Polyp characteristics in the 2 groups were similar. Delayed bleeding, defined as passage of bloody stool or massive hematochezia, occurred in two ulcers from each group 1-4 days after resection. No patient required transfusion or surgical treatment. The authors of this comparative study concluded that prophylactic clips did not decrease the occurrence of delayed bleeding after endoscopic polyp removal. Quintanilla et al. [8] reported similar results in a prospective evaluation for large pedunculated polyps. Indeed, prophylactic hemoclips applied pre-polypectomy for large pedunculated colon polyps were actually associated with further risk of mucosal deep erosions and perforation. For pedunculated colon polyps resected with electrocautery that proved to be malignant [1], no early or delayed bleeding events occurred during more than two decades of experience during which hemoclips were not required. Liaquat et al. [9] reviewed their experience over more than a decade after EMR-assisted removal of $\geq 2 \mathrm{~cm}$ polyps along with sessile and flat colorectal lesions. Multivariate analysis revealed that not clipping a polyp, location proximal to the splenic flexure, and large polyp size $(\geq 2 \mathrm{~cm})$ were associated with delayed bleeding. Finally, the cost 
efficacy of prophylactic hemoclip application after endoscopic removal of large polyps has been evaluated. Parikh et al. [10] used a computer-assisted decision analysis tool based on already published data with a reference case of a 50 -year-old patient with a single $1.0-1.5 \mathrm{~cm}$ polyp. The analyses were stated to be sensitive to costs of clips and hospitalization, number of clips placed, and clip effectiveness. The authors concluded that prophylactic placement of endoscopic clips after polypectomy was a costeffective strategy for patients receiving antiplatelet or anticoagulation therapy, but not otherwise. As always, these observational and retrospective studies await conformation from data generated in large randomized controlled trials.

Prophylactic use of modern hemoclip technology is generally recommended, particularly in patients at high risk that have undergone removal of large sessile polyps or if treated with anticoagulant drugs. Determining the true cost-effectiveness of treatment, particularly for reducing risk for a relatively rare event, may require much more data than are currently available. In the meantime, clinicians will continue to empirically determine use depending on their personal clinical assessment of bleeding risk.

\section{References}

1. Freeman HJ. Long-term follow-up of patients with malignant pedunculated colon polyps after colonscopic polypectomy. Can J Gastroenterol. 2013;27:20-24.
2. Su MY, Hsu CM, Ho YP, et al. Endoscopic mucosal resection for colonic non-polypoid neoplasms. Am J Gastroenterol. 2005; 100:2174-2179.

3. Hui AJ, Wong RM, Ching JY, Hung LC, Chung SC, Sung JJ. Risk of colonoscopic polypectomy bleeding with anticoagulants and antiplatelet agents: analysis of 1657 cases. Gastrointest Endosc. 2004;59:44-48.

4. Watabe H, Yamaji Y, Okamoto M, et al. Risk assessment for delayed hemorrhagic complication of colonic polypectomy: polyp-related factors and patient-related factors. Gastrointest Endosc. 2006;64:73-78.

5. Parra-Blanco A, Kaminaga N, et al. Hemoclipping for postpolypectomy and postbiopsy colonic bleeding. Gastrointest Endosc. 2000;51:37-41.

6. Feagins LA, Nguyen AD, Iqbal R, Spechler SJ. The prophylactic placement of hemoclips to prevent delayed post-polypectomy bleeding: an unnecessary practice? A case control study. Dig Dis Sci. 2014;59:823-828.

7. Shioji K, Suzuki Y, Kobayashi M, et al. Prophylactic clip application does not decrease delayed bleeding after colonoscopic polypectomy. Gastrointest Endosc. 2003;57:691-694.

8. Quintanilla E, Castro JL, Rabago LR, et al. Is the use of prophylactic hemoclips in the endoscopic resection of large pedunculated polyps useful? A prospective and randomized study. $J$ Interv Gastroenterol. 2012;2:183-188.

9. Liaquat H, Rohn E, Rex DK. Prophylactic clip closure reduced the risk of postpolypectomy hemorrhage: experience in 277 clipped large sessile or flat colorectal lesions and 247 control lesions. Gastrointest Endosc. 2013;77:401-407.

10. Parikh ND, Zanocco K, Keswani RN, Gawron AJ. A cost-efficacy decision analysis of prophylactic clip placement after endoscopic removal of large polyps. Clin Gastroenterol Hepatol. 2013;11: 1319-1324. 